\title{
efêmero e o perpétuo na fotografia
}

José Reinaldo Martins 1

Em Os tempos da fotografia: o efêmero e o perpétuo, Kossoy usa a sua experiência de pesquisador para discutir temas atuais como a fotografia digital, as manipulações da imagem e a fotorreportagem. Por isso mesmo é imprescindível para a compreensão de fenômenos complexos ligados à fotografia.

Com essa sua última publicação, Kossoy completa a trilogia que reúne outros dois livros: "Fotografia e história" e "Realidades e ficções na trama fotográfica”. A trilogia apresenta uma metodologia que permite interpretar as produções fotográficas considerando os aspectos históricos e culturais em que foram constituídas.

O ideal é ler as duas publicações anteriores para ter uma compreensão mais aprofundada do conteúdo de Os tempos da fotografia. Contudo, a leitura isolada do último livro da trilogia não invalida a apreensão de seu conteúdo e, ainda, é uma maneira interessante de ingressar no conjunto da obra do autor.

Professor titular da Escola de Comunicações e Artes da Universidade de São Paulo, Kossoy estuda a história da fotografia desde a década de 1970. Pesquisou a vida pessoal e a trajetória profissional de fotógrafos consagrados do século XIX e primeira metade do XX, entre os quais, Militão Augusto Azevedo, Marc Ferrez, Augusto Malta, Guilherme Gaensly e Hildegard Rosenthal.

Atualmente dedica especial atenção aos fotógrafos do século XIX e início do XX que ficaram no anonimato. Os primeiros dados sobre eles estão reunidos no "Dicionário Histórico-Fotográfico", de sua autoria. Em suas pesquisas, localizou Hércules Florence, um cientista que descobriu um método fotográfico no Brasil, em 1833, antes do daguerreótipo, lançado para o mundo, na França, em 1838/ 1839.

Kossoy oferece, no seu último livro, interpretações pautadas em pesquisas

ornalista com atuação nas as de educação, preservação de patrimônio histórico, turismo e meio ambiente. Tem mestrado em História da Fotografia, pela Escola de Comunicações e Artes da Universidade de São Paulo (ECA-USP) e especialização em Gestão da Comunicação, pela UFMA. históricas, destacando detalhes e sinuosidades surgidas das relações entre a fotografia e o meio cultural e social dos brasileiros.

Essas interpretações estão interligadas a alguns eixos que marcaram a sua trajetória de pesquisador. Uma dessas linhas é a defesa de que a fotografia, desde os tempos do daguerreótipo e do colódio úmido, mantém marcante característica: o caráter indicial. Esse aspecto já foi detalhado em livros anteriores, sendo retomado em Os tempos da fotografia. 
O autor já desmistificou a idéia de que a fotografia é a cópia da realidade. Ele a vê como uma criação, pois o fotógrafo seleciona, acentua e omite conteúdos. Como pesquisador, Kossoy fez essa descoberta antes do francês Philippe Dubois e outros estudiosos de renome internacional.

Na sua visão, a fotografia é uma imagem autoral e mantém em si somente indícios dos fatores que motivaram a sua criação. As pistas do ato criador começam a se diluir a partir do instante em que a imagem passa a ser vista pelo observador.

Mesmo que o observador tenha intimidade com os fatos motivadores da criação da imagem fotografia, ele encontra-se em outro momento, o que vai gerar novas sensações. Se estiver distante dos fatos, a situação fica mais complexa, e a fotografia, mais vulnerável a manipulações. Retomar as pistas/indícios do processo formador da fotografia é uma forma de identificar as manipulações. E é isso que Kossoy sugere em Os tempos da fotografia, através de exemplos contextualizados dentro da história.

O caráter indicial da fotografia está ligado aos fatores que motivaram a sua criação. $O$ ponto alto desse momento é o clique da câmara fotográfica: um instante que ele chama de efêmero, apesar de constituído em um tempo e espaço cultural e social complexo e momentaneamente estável.

Depois da efêmera criação, a fotografia perpetua-se fixada em um papel, ou apresentada na tela do computador. Vai para um álbum ou para um jornal ou um site da Internet. Passa a manter um diálogo com quem a olha, apartada do momento de sua concepção.

Evidentemente, a fotografia se perpetua, em termos, como alerta o autor, pois a imagem gravada em papel, reproduzida em um jornal, ou transferida para o computador pode ser rasgada ou deletada.

No mundo virtual, o indicial da fotografia encontra-se ameaçado pelas facilidades de manipulação de seu conteúdo. Essa nova situação coloca em risco a sobrevivência das pistas (índices) geradas no tempo histórico da criação. Esse é um tema que permeia Os tempos da fotografia.

Para Kossoy, na relação da fotografia com quem a vê é estabelecida "certa conexão... que ultrapassa o conteúdo temático" (2007, p. 149). O observador, ao olhar para a fotografia, pode experimentar algo "cuja presença pressentimos, mas que não está ali, fisicamente".

Kossoy adverte que as conexões entre a fotografia e o observador ao qual ele se refere diferem-se do punctum, de Barthes. Apresentam-se mais como portais que possibilitam o surgimento de afinidades com imagens de países e pessoas que nunca visitamos ou vimos. Talvez as sensações sentidas pelo observador seja uma das causas de a fotografia permanecer atrativa em pleno século XXI. Mantém-se atual justamente pela capacidade de intermediar com sucesso a relação do homem com seu meio.

Em Os tempos da fotografia, Kossoy denuncia manipulações da fotografia e fomenta debates sobre a diversidade de um tema carregado de conexões e que, por isso mesmo, foge de respostas apressadas.

A fotografia não é ingênua. Ao longo de sua trajetória incriminou inocentes, discriminou e humilhou pessoas por causa da origem racial e cultural ou por ideais políticos. As imagens etnográficas de negros e índios no século XIX é um exemplo perverso.

As manipulações mais indevidas são identificadas pelo autor em períodos de ditaduras, como na Era Vargas, no Brasil, dos militares latino-americanos nas décadas de 1960/1970, na Europa de Hitler ou na Espanha de Francisco Franco, que resistiu até a década de 1970. Todos esses temas estão em Os tempos da fotografia. 
A fotografia, como mostra esse último livro de Kossoy, soube, também, driblar as pressões das ditaduras e apresentar momentos de fulgor. Hildegard Rosenthal da São Paulo das décadas de 1930/1940, no tempo de Vargas, é um exemplo. Trabalhos como os de Rosenthal, que inclui o cotidiano de pessoas simples, estarão sempre indiciando as lacunas da vida, como se fossem pontas de icebergs. São atuais, independentemente da tecnologia em voga. Até porque, ao deslizar entre a informação e a emoção, a fotografia é mais que uma tecnologia. Permanece com parte inefável da cultura, quase que indiferente ao avanço das imagens em movimento.

Os tempos da fotografia mostra que a fotografia, apesar das manipulações por ditaduras cruéis, proporciona alegrias diversas, como em festas de aniversários, inaugurações, casamentos, passeios e em registro de paisagens urbanas e da natureza. E é a eterna dependência que tem da criatividade e das emoções que a mantém evidente.

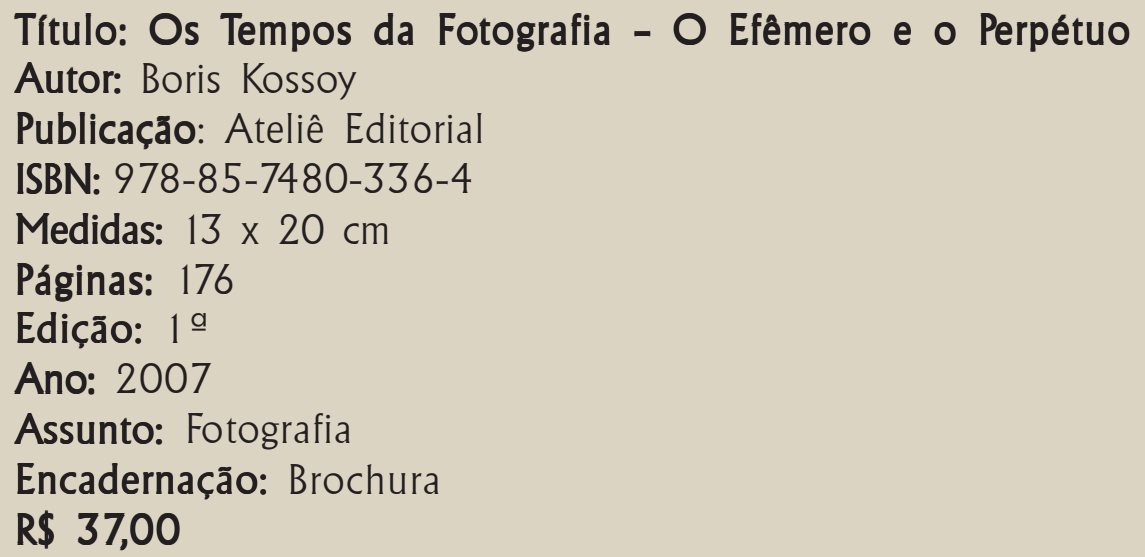

Outras publicações de Kossoy

Hercules Florence 1833: a descoberta isolada da fotografia no Brasil. 3. ed. São Paulo: Edusp, 2006.

. Luzes e sombras da metrópole: um século de fotografias em São Paulo (1850-1950). In: PORTA, Paula. História da Cidade de São Paulo. A Cidade no Império 1823-1889. São Paulo: Paz e Terra, 2004, v.2, p. 385-455.

Construção e desmontagem da informação fotográfica: teoria e história. Revista USP, n. 62, p. 224-232, jun./ago. 2004.

Fotografia e história. 3. ed., São Paulo: Ateliê, 2003.

Dicionário histórico-fotográfico brasileiro: fotógrafos e ofício da fotografia (1833-1910). São Paulo: Instituto Moreira Salles, 2002.

Realidades e ficções na trama fotográfica. São Paulo: Ateliê, 2000.

Militão Augusto de Azevedo e a documentação fotográfica de São Paulo (1862-1887): recuperação da cena paulista através da fotografia. São Paulo: FESP, 1988.

São Paulo 1900. Imagens de Guilherme Gaensly. São Paulo: Kosmos/ CBPO, 1988.

Origens e expansão da fotografia no Brasil. Século XIX. Rio de Janeiro: MEC/Funarte, 1980. 